\title{
The Presentation Pattern of Celiac Disease in Central India - A Prospective Study in Children
}

\section{Shashi Sharma, Richa, Sakshee Madan, Tanu Singh and Bharat Bhushan Sharma}

Department of Paediatrics, SGT Medical College, Shree Guru Gobind Singh Tricentenary

University, Gurugram, Haryana, India

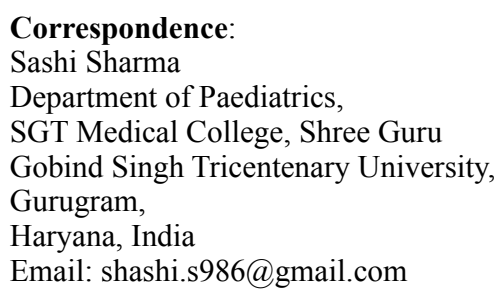

Email: shashi.s986@gmail.com

DOI: $10.3126 /$ jnps.v40i3.29509

Submitted on: 2020-06-18

Accepted on: 2020-10-04

\section{Acknowledgements: None}

Funding: Nil

Conflict of Interest: None declared

Permission from IRB: Yes
To cite this article: Sharma S, Richa, Madan S, Singh T, Sharma BB. The Presentation Pattern of Celiac Disease in Central India - A Prospective Study in Children. J Nepal Paediatr Soc. 2020;40(3):255-60.

\section{ABSTRACT}

Introduction: Celiac disease is a common immune-mediated enteropathy characterised by villous atrophy. It has clinical phenotypes of classic, non-gastrointestinal and silent / subclinical or potential depending on the clinical phenotype. We intended to assess the clinical features and laboratory findings of patients with celiac disease and compare the classical celiac disease with nongastrointestinal celiac disease.

Methods: This is a two-year cross-sectional study conducted at our institute. Children from one year to 18 years diagnosed as celiac disease based on the revised ESPGHAN criteria were enrolled. They were categorised into classical celiac disease and non-gastrointestinal celiac disease (atypical) and their clinical features and laboratory findings were documented.

Results: Forty patients had confirmed celiac disease. The mean age of the subjects was $6.84 \pm 4.41$ years, with male : female ratio of 1.85 . The commonest presentations were failure to thrive $(75 \%)$, anaemia $(70 \%)$, associated rickets $(67.5 \%)$ and $32 \%$ diarrhoea. Patients with classical features were identified at an earlier age than those with non-gastrointestinal celiac disease. Marsh grade $3 \mathrm{a}$ and above were more commonly seen in classical celiac disease. The most common symptom among the classical group was abdominal distension. Among the non-gastrointestinal group, the most common symptom was anaemia. Vitamin D deficiency was almost equally present in both groups.

Conclusions: Non-gastrointestinal celiac disease is not uncommon among our population. Patients with clinical features of recurrent abdominal pain, vomiting, failure to thrive, or merely short stature and refractory anaemia should be worked up for celiac disease.

Keywords: Biopsy; Celiac disease; Diarrhoea; Serum tissue Transglutaminase antibodies

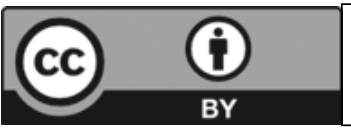

This work is licensed under creative common attribution 3.0 license 


\section{INTRODUCTION}

Celiac disease (CD) is a common genetically related food intolerance to dietary gluten and other related proteins, which are a component of wheat, rye, and barley. It is an immune-mediated enteropathy characterised by a variable degree of damage to small intestinal mucosa leading to villous atrophy and flattening in genetically susceptible individuals. ${ }^{1}$ The current prevalence of paediatric celiac disease is estimated to be around $1 \%$ in the general population worldwide. ${ }^{2}$ However, there has been great variability in its prevalence according to the geographic area. In a study conducted in the year 2018 by Singh P et al., it has been suggested that the pooled global seroprevalence of CD was $1.4 \%$ whereas biopsyconfirmed CD was $0.7 \%{ }^{3}$ Celiac disease has a broad clinical spectrum categorised as classic, nongastrointestinal, silent / subclinical or potential depending on the clinical phenotype. In classical $\mathrm{CD}$, the patient presents with features of malabsorption such as diarrhoea, abdominal distension, steatorrhea, weight loss, or growth failure. In non-gastrointestinal $\mathrm{CD}$, patients have few or no gastrointestinal symptoms. They have predominantly extra-intestinal symptoms such as anaemia, short stature, rickets, failure to thrive, and recurrent oral ulcers. ${ }^{4-6}$ In subclinical $\mathrm{CD}$, the disease is below the threshold of clinical detection without symptoms or signs. In potential $\mathrm{CD}$, the patient has an abnormal antibody test but normal intestinal histology.

It has been observed that many cases of CD remain undiagnosed until they present with severe complications in adulthood. ${ }^{7}$ Typically, the inflammation in CD includes an increased intraepithelial lymphocyte (IEL) count, most often $>25 / 100$ cells. Another feature of CD is that it incorporates an adaptive T-cell-mediated response (to gluten) and it occurs in people who are DQ2 and DQ8 positive. ${ }^{8}$ Increasingly, the presence of specific endomysial antibodies (EMA), anti-tissue transglutaminase antibodies (TGA), and / or deamidated antigliadin antibodies (DGP) plays an important role in the serological work-up for CD. These antibodies strongly support the diagnosis of CD. For initial testing, the combination of total IgA and TGA-IgA antibodies is recommended. With high TGA-IgA values $>10$ times, the upper limit of normal and a positive EMA-IgA in a second serum sample a confirmatory diagnosis of $\mathrm{CD}$ can be made. However low titers $(<10$ times upper limit of normal) of TGA-IgA antibodies should undergo biopsies for diagnosis according to revised ESPGHAN (European Society for Paediatric Gastroenterology, Hepatology and Nutrition) criteria. ${ }^{9}$ The study aimed to assess the clinical spectrum and laboratory findings in paediatric patients with biopsy-proven celiac disease. We compared these features among classical celiac disease and the non-gastrointestinal celiac disease in our population.

\section{METHODS}

This is a two-year cross-sectional study conducted at SGT Medical College, Haryana, India from July 2017 to June 2019. Children of age from one year to 18 years of either gender diagnosed as celiac disease were enrolled into the study. All children with TGA-IgA levels $>10 \mathrm{U} / \mathrm{ml}$ with a normal total IgA levels underwent upper GI endoscopy with four biopsies from distal duodenum and one from the bulb during a gluten-containing diet. The information recorded for analysis included age, gender, clinical presentation, serological marker (IgA-TTG) levels, small intestinal mucosal biopsy interpretation using Marsh grading, haemoglobin, serum vitamin D levels, and radiological evaluation of wrist for features of rickets.

The data was compiled, entered, and analysed using Epi info version 7.2. The qualitative variables were expressed in terms of proportions and to test the difference between two proportions, chi-square or Fisher exact test was used. The quantitative variables were expressed in terms of mean and standard deviation. To test the difference between the two means, student t-test was used. All analysis was two-tailed and the significance level was set at 0.05 . All patients were enrolled in the study after taking informed consent from parents / guardians. Approval was taken from the Institutional Ethical Committee before initiation of the study.

\section{RESULTS}

A total of 40 patients had confirmed celiac disease according to the inclusion criteria. The mean age of 
1 to 5 5 to 10 10 to 15 $>15$

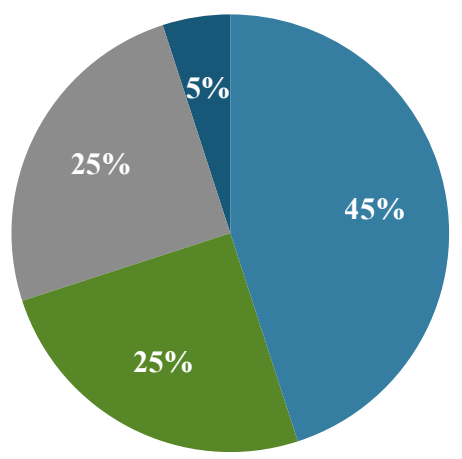

Figure 1. Pie chart showing the distribution of the study subjects based on age group (years)

the subjects was $6.84 \pm 4.41$ years with an age range of a minimum of one year and maximum of 16 years. Most common age group was between one to five years followed by five to 10 years (Figure 1).

Male to female ratio was 1.85 . The most common chief complaint was failure to thrive $(75 \%)$ whereas around $32 \%$ of patients had diarrhoea at the time of presentation (Figure 2). It was also seen that patients with classical features were identified at an earlier age. The non-gastrointestinal celiac disease had an extended duration of symptoms prior to diagnosis as shown in Table 1.

Abdominal distension, failure to thrive, oral ulcers, short stature, and vomiting were significantly higher among the classical group when compared with the non-gastrointestinal group as shown in Table 2 . Short stature can be the only presentation of celiac disease.

Marsh grade 3a and above were more commonly seen in classical celiac disease. The most common grading noticed among the study subjects was $3 \mathrm{c}$ grade $(47.50 \%)$. As the grade increased, the proportion of classical celiac disease increased significantly $(\mathrm{p}<0.05)$ as shown in Table 3 .

The laboratory parameters suggested that vitamin D deficiency and low haemoglobin was almost equally present in both the groups as there was no significant difference in their levels in both the groups.

\section{DISCUSSION}

Celiac disease, a common disorder in children traditionally presents between the age of six months and 24 months with classical symptoms. ${ }^{10}$ However as our study demonstrates, it is not limited to that particular age group. The mean age group was 6.84 \pm 4.41 years. It is evident in many series that patients with classical presentation were identified at an earlier age. This was corroborated in our study too. Similarly, the age of appearance of symptoms and diagnosis was significantly higher in nongastrointestinal celiac disease. A similar study conducted by Mohindra et al. also suggested delayed recognition of disease. ${ }^{11}$ The sex ratio in

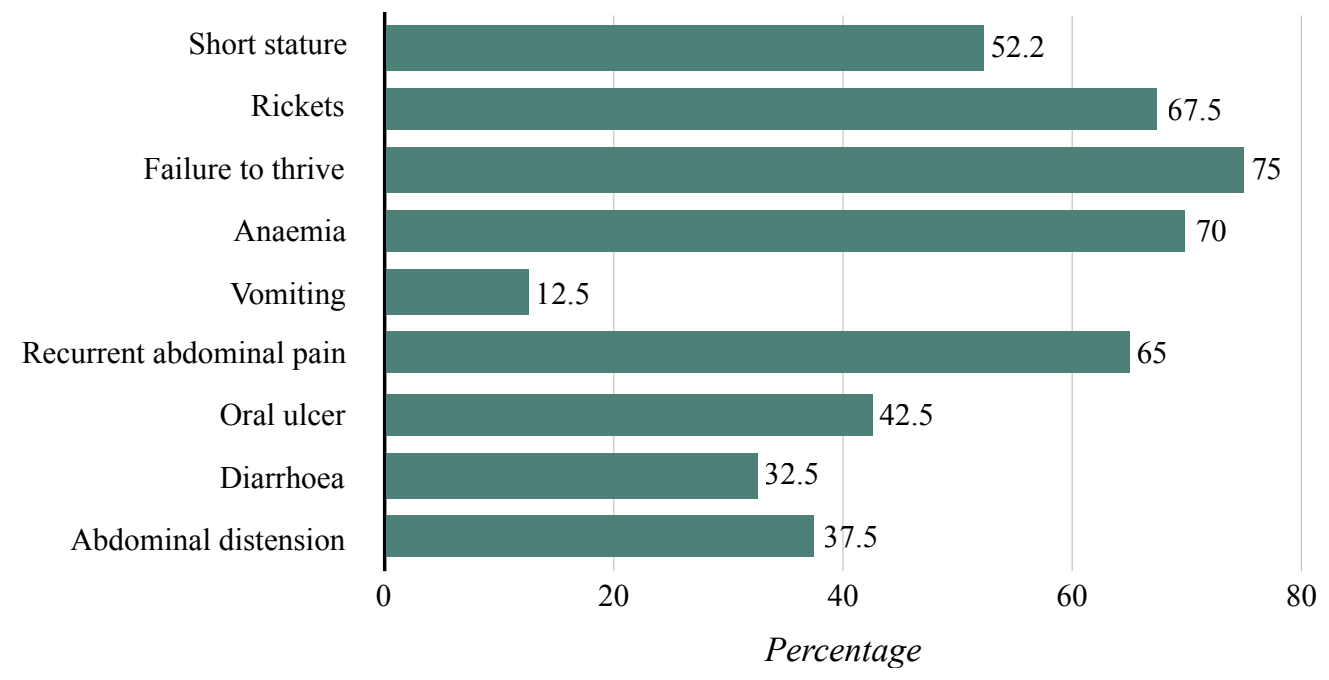

Figure 2. Distribution of the study subjects based on chief complaints and other associated diseases $(n=40)$ 
Table 1. Comparison between the classical and nongastrointestinal type of celiac disease based on demographic factors

\begin{tabular}{|lccccc} 
Factors & \multicolumn{2}{c}{$\begin{array}{c}\text { Classical } \\
(\mathbf{n}=\mathbf{1 3})\end{array}$} & $\begin{array}{c}\text { Non } \\
\text { gastrointestinal } \\
(\mathbf{n}=\mathbf{2 7})\end{array}$ & $\begin{array}{c}\text { p- } \\
\text { value }\end{array}$ \\
\cline { 2 - 5 } & Mean & SD & Mean & SD & \\
\hline Age & 3.39 & 1.74 & 8.50 & 4.37 & 0.0002 \\
\hline
\end{tabular}

between male to female in our study was 1.8 , which was in line with previous studies stating higher prevalence among males than females as suggested by Altwaty and Elbargathy et al. and Sharma et al. ${ }^{12,13}$ Surprisingly, many studies conducted in other countries have shown to have female preponderance more than males.

Children with CD can present with a wide spectrum of manifestations. Our study has also demonstrated the same. Beside common GI symptoms like diarrhoea, pain abdomen, abdominal bloating etc this study has shown that even short stature, rickets or anaemia may be the presentation of celiac disease. We have found that both classical and nongastrointestinal types are seen, the latter being more common among our population. According to Ludvigsson et al, the main clinical presentation of celiac disease in the paediatric population included persistent diarrhoea. ${ }^{14}$ Mohindra et al. also observed that diarrhoea, abdominal distension, and abdominal pain are the main clinical manifestations of celiac disease in their study. ${ }^{11}$ On the contrary, a higher proportion of cases $(20-40 \%)$ did not have diarrhoea in $\mathrm{CD}$ among western studies.

The most common symptoms among the classical group were abdominal distension, failure to thrive, oral ulcers, and anaemia. Danish Abdul et al. and Dinler et al. also reported abdominal distension as a predominant feature in patients with classical celiac disease. ${ }^{15,16}$ A study conducted by Letizia et al. showed that $43 \%$ of patients experienced only recurrent abdominal pain. ${ }^{17}$ In our study, $63 \%$ of patients had recurrent abdominal pain as the manifestation of $\mathrm{CD}$ in non-gastrointestinal celiac disease and $69 \%$ of patients in the classical group. In our experience, all patients in the classical group had failure to thrive whereas only $63 \%$ of patients in the non-gastrointestinal group had failure to
Table 2. Comparison between the classical and nongastrointestinal type of celiac disease based on signs and symptoms

\begin{tabular}{|c|c|c|c|c|c|}
\hline \multirow[t]{2}{*}{ Factors } & \multicolumn{2}{|c|}{$\begin{array}{l}\text { Classical } \\
(n=13)\end{array}$} & \multicolumn{2}{|c|}{$\begin{array}{c}\text { Non } \\
\text { gastrointestinal } \\
(\mathrm{n}=27) \\
\end{array}$} & \multirow[t]{2}{*}{$\begin{array}{c}\text { p- } \\
\text { value }\end{array}$} \\
\hline & Value & $\%$ & Value & $\%$ & \\
\hline $\begin{array}{l}\text { Abdominal } \\
\text { distension }\end{array}$ & 13 & 100.00 & 2 & 7.41 & $<0.001$ \\
\hline Anemia & 10 & 76.92 & 18 & 66.67 & 0.5073 \\
\hline $\begin{array}{l}\text { Failure to } \\
\text { thrive }\end{array}$ & 13 & 100.00 & 17 & 62.96 & 0.0163 \\
\hline Oral ulcer & 12 & 92.31 & 5 & 18.52 & $<0.001$ \\
\hline $\begin{array}{l}\text { Recurrent } \\
\text { abdominal } \\
\text { pain }\end{array}$ & 9 & 69.23 & 17 & 62.96 & 0.6790 \\
\hline Rickets & 9 & 69.23 & 18 & 66.67 & 0.8771 \\
\hline $\begin{array}{l}\text { Short } \\
\text { stature }\end{array}$ & 3 & 23.08 & 18 & 66.67 & 0.0097 \\
\hline Vomiting & 5 & 38.46 & 0 & 0 & 0.0005 \\
\hline
\end{tabular}

thrive. This is quite similar to Aziz S et al. where around $61 \%$ of patients had failure to thrive. ${ }^{18}$

Among the non-gastrointestinal group the most common symptoms of $\mathrm{CD}$ were anaemia, short stature, and rickets $(67 \%)$. It is seen that short stature can be the only presentation of $\mathrm{CD}$. Hence many studies recommend screening for $\mathrm{CD}$ among children with short stature, especially in severely stunted children. Sherwani RK et al. also observed pallor in all of the study subjects while Misha Khalid et al. showed $67 \%$ of patients with nongastrointestinal celiac disease presented with anaemia. ${ }^{15,19}$ Most of the patients in our study had Marsh grade 3 lesion, the most common being 3c (total villous atrophy). This was similar to a study done by Saeed et al. Topal et al. found that $52 \%$ of patients with celiac disease had vitamin D deficiency at the time of presentation. ${ }^{20}$ In our study serum vitamin $\mathrm{D}$ and haemoglobin levels were deficient equally in both the groups. Hence an initial screening is required in all patients with $\mathrm{CD}$.

Our study has tried to highlight that the general prevalence of $\mathrm{CD}$ might be more, even in our population. The varied presentation of $\mathrm{CD}$ should always be kept in mind while evaluating children. Although it is a gastrointestinal disease, the presentation might involve other systems besides 
Table 3. Comparison between the classical and nongastrointestinal type of celiac disease based on Marsh grading

\begin{tabular}{|c|c|c|c|c|c|}
\hline \multirow[t]{2}{*}{$\begin{array}{l}\text { Marsh } \\
\text { Grading }\end{array}$} & \multicolumn{2}{|c|}{$\begin{array}{c}\text { Classical } \\
(n=13)\end{array}$} & \multicolumn{2}{|c|}{$\begin{array}{c}\text { Non } \\
\text { gastrointestinal } \\
(\mathrm{n}=27)\end{array}$} & \multirow[t]{2}{*}{$\begin{array}{c}\text { P- } \\
\text { value }\end{array}$} \\
\hline & Value & $\%$ & Value & $\%$ & \\
\hline 2 & 0 & 0 & 7 & 25.93 & 0.0421 \\
\hline $3 a$ & 2 & 15.38 & 5 & 18.52 & \\
\hline $3 b$ & 2 & 15.38 & 5 & 18.52 & \\
\hline $3 c$ & 9 & 69.23 & 10 & 37.04 & \\
\hline
\end{tabular}

gastrointestinal. Our study is a limited study conducted in a single centre with relatively lesser number of study subjects. Thus, it is difficult to extrapolate our findings to the general population of our country. Hence, our findings should be further analysed with larger multi-centric studies. gastrointestinal types are seen, the latter being more common among our population. Around $70 \%$ of patients did not have diarrhoea at the time of the presentation. It was also seen that patients with classical symptoms were diagnosed earlier in the course of the disease. Hence patients presenting with features of recurrent abdominal pain, vomiting, failure to thrive, or merely short stature and refractory anaemia should prompt physicians to think and investigate for celiac disease to avoid complications associated with untreated cases.

\section{CONCLUSIONS}

Children with $\mathrm{CD}$ can present with a wide spectrum of manifestations. Both classical and non-

\section{REFERENCES}

1. Silano M, Agostoni C, Guandalini S. Effect of the timing of gluten introduction on the development of the celiac disease. World J Gastroenterol. 2010; 16 (16):1939-1942. DOI:10.3748/wjg,v16.i16.1939

2. Gupta R, Reddy DN, Makharia GK, Sood A, Ramakrishna BS, Yachha SK, et al. India task force for celiac disease: current status. World J Gastroenterol. 2009;15:6028-6033. DOI: 10.3748/wjg.15.6028

3. Singh P, Arora A, Strand Tor A, Leffler D, Catassi C, Green Petal. Global Prevalence of Celiac Disease: Systematic Review and Meta-analysis. Clin. Gastroenterol. Hepatol. 2018;16:823-836. DOI: 10.1016/j.cgh.2017.06.037

4. Celiloglu C, Karabiber H, Selimoglu MA. A typical presentation of celiac disease. Turk J Pediatr. 2011;53(3):241-9. DOI:10.1159/000116769.

5. Mody RJ, Brown PI, Wechsler DS. Refractory iron deficiency anemia as the primary clinical manifestation of celiac disease. J Pediatr Hematol Oncol. 2003;25(2):169-72. DOI: 10.1097/00043426-200302000-00018

6. Queiroz MS, Nery M, Cancado EL, Gianella-Neto D, Liberman B. Prevalence of celiac disease in Brazilian children of short stature. Braz J Med Biol Res. 2004;37(1):55-60. DOI: 10.1590/S0100-879X2004000100008.

7. Caio C, Volta U, Sapone A, Leffler DA, De Geordio R, Catassi C, et al. Celiac disease: a comprehensive current review. Caio et al BMC Medicine. 2019;17:142. DOI: 10.1186/s12916-019-1380-z

8. Martin F Kagnoff. Overview and Pathogenesis of Celiac Disease. Gastroenterology. 2005;128:S10-S18. DOI: 10.1053/j.gastro.2005.02.008

9. Husby S, Koletzko S, Korponay-Szabó I, Kurppa K, Mearin L, Ribes-Koninckx C, et al. European Society Paediatric Gastroenterology, Hepatology and Nutrition Guidelines for Diagnosing Coeliac Disease 2020. Jan2020 ; 70(1):141-156. DOI: 10.1097/MPG.0000000000002497.

10. Alessio Fasano. Clinical Presentation of Celiac Disease in the Pediatric Population. Gastroenterology. 2005 Apr; 128(4 Suppl 1): S68-73. DOI: 10.1053/j.gastro.2005.02.015. 
11. Mohindra S, Yachha SK, Srivastava A, Krishnani N, Aggarwal R, Ghoshal UC, et al. Coeliac disease in Indian children: Assessment of clinical, nutritional and pathologic characteristics. J Health Popul Nutr. 2001;19(3):204-8. PMID:11761775.

12. Al-Tawaty AI, Elbargathy SM. Celiac disease in north-eastern Libya. Ann Trop Paediatric. 1998;18:27-30. DOI: 10.1080/02724936.1998.11747922.

13. Sharma M, Mandot S. Prevalence and clinical profile of celiac disease among malnourished children in South Rajasthan, India. Int. J. Contemp. Pediatrs. 2018;5(3):997-1002 DOI:10.18203/2349-3291.ijcp20181529.

14. Ludvigsson JF, Bai JC, Biagi F, Card TR, Ciacci C, Ciclitira PJ, et al. Diagnosis and management of adult coeliac disease: guidelines from the British Society of Gastroenterology. Gut. 2014;63(8):1210-28. DOI:10.1136/ gutjnl-2013-306578.

15. Aziz DA, Kahlid M, Memon F, Sadiq K. A spectrum of Celiac disease in Paediatric population: Experience of Tertiary Care Center from Pakistan. Pak J Med Sci. 2017:33(6):1301-6. DOI:10.12669.pjms.336.13489.

16. Dinler G, Atalay E, Kalayc1 AG. Celiac disease in 87 children with typical and atypical symptoms in the Black Sea region of Turkey. World J Pediatr. 2009;5(4):282-6. DOI: 10.1007/s12519-009-0053-y.

17. Letizia M, Tolone C, Belfiore I, Pellino V, Piccirillo M, Rinaldi FO, et al. Recurrent abdominal pain and celiac disease. Dig Liver Dis. 2013;45:e288. DOI: 10.1016/j.dld.2013.08.193.

18. Aziz S, Muzaffar R, Zafar MN, Mehnaz A, Mubarak M, Abbas Z, et al. Celiac disease in children with persistent diarrhea and failure to thrive. J Coll Physicians Surg. 2007;17(9):554-7. PMID: 17903405

19. Sherwani RK, Alam S, Akhtar K, Abid B, Rahman K, Mehdi R. Prevalence of iron deficiency anemia in chronic diarrhea and celiac disease: a western UP experience. Indian J Hematol Blood Transfusion. 2008;24(1):12-5. DOI: $10.1007 / \mathrm{s} 12288-008-0017-8$

20. Topal E, Catal F, Acar NY, Ermiştekin H, Sinanoğlu MS, Karabiber H, et al. Vitamin and mineral deficiency in children newly diagnosed with celiac disease. Turk J Med Sci. 2015;45(4):833-836. DOI: 10.3906/sag-1408-94. 